ABSTRACT: Age significantly influences the detection thresholds to noxious heat; such thresholds depend on responses in the cerebral cortex to thermal stimuli and the psychophysical perception of such responses. To understand the influence of age on cerebral responses, we used contact heat-evoked potentials (CHEPs) to investigate the physiology of cerebral responses to thermal stimuli in 70 healthy subjects (33 men and 37 women, $39.56 \pm 12.12$ years of age). With heat stimulation of fixed intensity $\left(51^{\circ} \mathrm{C}\right)$ on the distal forearm and distal leg, CHEPs revealed consistent waveforms with an initial negative peak (N1 latency: $398.63 \pm 28.55$ and $449.03 \pm$ $32.21 \mathrm{~ms}$ for upper and lower limbs) and a later positive peak (P1 latency: $541.63 \pm 37.92$ and $595.41 \pm 39.24 \mathrm{~ms}$ for upper and lower limbs) with N1-P1 interpeak amplitude of $42.30 \pm 12.57 \mu \mathrm{V}$ in the upper limb and $39.67 \pm 12.03 \mu \mathrm{V}$ in the lower limb. On analyses with models of multiple linear regression, N1-P1 amplitudes were negatively correlated with age and $\mathrm{N} 1$ latencies were correlated with gender, with females having shorter latencies. The verbal rating scale (VRS) for pain perception was higher in females than males, and decreased with aging. In addition, VRS paralleled changes in N1-P1 amplitude and N1 latency; the higher the VRS, the shorter the $\mathrm{N} 1$ latency and the higher the N1-P1 amplitude. These results provide evidence that CHEPs are influenced significantly by aging, corresponding to aging-related changes in thermal pain perception.

Muscle Nerve 36: 30-38, 2007

\title{
EFFECTS OF AGING ON CONTACT HEAT-EVOKED POTENTIALS: THE PHYSIOLOGICAL ASSESSMENT OF THERMAL PERCEPTION
}

\author{
CHI-CHAO CHAO, MD, ${ }^{1}$ SUNG-TSANG HSIEH, MD, PhD, ${ }^{1,2}$ MING-JANG CHIU, MD, PhD, ${ }^{1}$ \\ MING-TSUNG TSENG, MD, ${ }^{1,3}$ and YANG-CHYUAN CHANG, MD ${ }^{1}$ \\ ${ }^{1}$ Department of Neurology, National Taiwan University Hospital, 7 Chung-Shan South Road, \\ Taipei 10002, Taiwan \\ ${ }^{2}$ Department of Anatomy and Cell Biology, National Taiwan University College of Medicine, Taipei, Taiwan \\ ${ }^{3}$ Section of Neurology, Department of Internal Medicine, Far Eastern Memorial Hospital, Taipei, Taiwan
}

Accepted 26 March 2007

Impaired sensations to thermal stimuli are common neurological deficits in clinical practice. The perception of thermal stimuli depends on serial neural systems including peripheral terminals in the skin, primary afferent $\mathrm{A} \delta$ and $\mathrm{C}$ fibers, and excitatory and inhibitory mechanisms within the central nervous system. ${ }^{26,41}$ Aging has profound effects on structural and biochemical components at different levels of the neural axis. ${ }^{5,15,34}$ The overall outcome at the cerebral level with adequate time resolution, however, has rarely been explored. ${ }^{14}$ Several groups,

Abbreviations: CHEP, contact heat-evoked potential; LEP, laser-evoked potential; VRS, verbal rating scale

Key words: age; A $\delta$ fiber; contact heat-evoked potentials; gender; thermal pain

Correspondence to: Y.-C. Chang; e-mail: ycchang@ha.mc.ntu.edu.tw

(C) 2007 Wiley Periodicals, Inc.

Published online 14 May 2007 in Wiley InterScience (www.interscience. wiley.com). DOI 10.1002/mus.20815 including ours, have demonstrated that aging influences thermal thresholds. ${ }^{12,23}$ There are grading increases in thermal thresholds between young, middle-aged, and elderly subjects; thermal thresholds of women are lower than those of men..23 There are also age-related increases in thermal pain thresholds and in reaction time of reporting pain to thermal stimuli, ${ }^{4}$ indicating a decline in pain sensitivities with age. It is not clear whether there are corresponding physiological signals underlying these differences if similar settings of measuring thermal thresholds are used.

Traditionally, the perception of thermal and noxious stimuli is assessed with psychophysical methods based on a quantitative expression of subjective feeling, such as the visual analog scale or verbal rating scale (VRS) to measure the intensity of pain, and quantitative sensory testing to measure thermal thresholds. ${ }^{7,32}$ In the brain, the areas responsible for 
pain perception can be resolved by neuroimaging studies. ${ }^{8}$ However, the temporal resolution of these imaging studies may not necessarily reflect instantaneous neural activities at the level of milliseconds. Studies have documented that recording laserevoked potentials (LEPs) is a reliable method to investigate thermal pain pathways with adequate temporal resolution, by selectively activating $\mathrm{A} \delta$ - and C-fiber pathways. ${ }^{3,25,38}$ However, a punctate area of stimulation that does not simulate the real-life experience of thermal stimulation, high cost, and the potential risk of skin damage prevent LEPs from large-scale clinical use. Thus, an assessment with an adequate temporal resolution and stimulation area is needed to complement neuroimaging studies for understanding how the brain processes thermal stimuli.

Recently, the incorporation of a heat stimulator into a conventional evoked potential recorder has been used to detect contact heat evoked potentials (CHEPs); this approach utilizes a newly developed heat-foil technology to create a rapid heating rate (up to $70^{\circ} \mathrm{C} / \mathrm{s}$ ), which can deliver thermal stimuli repeatedly to a large area of skin and can evoke cerebral responses based on the target temperature and the site of stimulation. ${ }^{6,10}$ The responses from A $\delta$ fibers, maximally recorded at the vertex and presumably originating from the middle cingular area, ${ }^{19,35}$ are better defined and consistent compared with those from $\mathrm{C}$ fibers. ${ }^{10,40}$ This new recording technique provides a non-invasive assessment for investigating thermal pathways and can specifically determine the physiological changes that underlie the perception of, for example, intensity of pain. However, it remains unknown whether CHEPs are affected by age. ${ }^{37,39}$

To address the influence of age on CHEPs, we analyzed the effects of age and gender on amplitudes and latency of CHEPs recorded from the vertex.

\section{SUBJECTS AND METHODS}

Subjects. Healthy subjects of different ages were recruited from those visiting the hospital for health check-up as described previously. ${ }^{23}$ Each subject had laboratory tests to exclude systemic metabolic disorders, including diabetes mellitus, uremia, and hyperlipidemia. In addition, staff neurologists reviewed the subjects' personal history with detailed questionnaires and performed neurological examinations to ensure that they did not have a neurological disorder. Only subjects free from sensory symptoms and neurological signs were included in this study. In total, there were 33 men (40.94 \pm 13.78 years of age, range 22-67 years) and 37 women (38.32 \pm 10.46 years of age, range 24-62 years). There was no significant difference in age distribution between male and female subjects.

In addition to body height, the lengths of the upper and lower limbs were measured. The length of the upper limb was measured from the spinous process of the seventh cervical vertebral body to the tip of the middle finger. The length of the lower limb was defined as the distance between the upper border of the lateral iliac crest and the heel.

Our institutional review board approved this study, and informed consent was obtained from all participants before the procedures.

Procedures. A contact heat-evoked potential stimulator (Medoc, Ltd., Ramat Yishai, Israel), with a thermode having a circular contact area of $27 \mathrm{~mm}$ in diameter $\left(572 \mathrm{~mm}^{2}\right)$, was used for delivering heat stimulation. ${ }^{6,10}$ The thermode comprised two layers of stimulators working together: the external and lower layers. The external layer consists of a heating foil. The heating thermofoil (Minco Products, Inc., Minneapolis, Minnesota) is covered with a $25-\mu \mathrm{m}$ layer of thermoconductive plastic (Kapton, thermal conductivity at $23^{\circ} \mathrm{C}$ of $0.1-0.35 \mathrm{~W} / \mathrm{m} / \mathrm{K}$ ). Two thermocouples (electronic thermal sensors) are embedded at $10 \mu \mathrm{m}$ within this conductive coating, which contacts the skin directly, thus providing an estimate of skin temperature at the thermode surface. ${ }^{10,40}$ Throughout the study the stimulus temperature was defined as the temperature of thermofoil applied to the skin. The lower layer is a peltier element with two thermistors (electronic thermal sensors). The external thermofoil permits a very rapid heating rate, up to $70^{\circ} \mathrm{C} / \mathrm{s}$, and the lower layer peltier allows a fast cooling rate, up to $40^{\circ} \mathrm{C} / \mathrm{s}$. Cooling begins immediately after the thermode reaches its target stimulus temperature, which is set by the manufacturer's algorithms.

Subjects lay on a table with eyes closed, in a warm $\left(25^{\circ} \mathrm{C}\right)$ semi-darkened room. The stimulation site for the upper limb was at the right dorsal forearm, $5 \mathrm{~cm}$ proximal to the midpoint between the medial and lateral styloid processes, and for the lower limb was in the lateral leg $10 \mathrm{~cm}$ proximal to the right lateral malleolus. The adaptive temperature (baseline) of the thermode was set at $35^{\circ} \mathrm{C}$ for all stimuli and the heat pulse was delivered from baseline to $51^{\circ} \mathrm{C}$. The interstimulus intervals varied at around 20-22 s. The stimuli were terminated when 16 evoked potentials had been recorded. Subjects were asked to pay attention to the stimulation site during the study. The perception of pain intensity was reported $3 \mathrm{~s}$ after 
each stimulus using the VRS $(0-10)$, where $0=$ no sensation, $4=$ pain threshold, and $10=$ intolerable pain.

CHEPs were recorded with a Nicolet Bravo evoked potential system (Nicolet Biomedical, Madison, Wisconsin). The recording electrodes were placed at the $\mathrm{Cz}$ and $\mathrm{P} 3$ sites of the 10-20 system, and the present report was based on the data recorded from the $\mathrm{Cz}$ (vertex) area. The reference was set at the left ear lobe and the ground was placed at Fpz. For control of artifacts, we monitored the electrooculogram from supra- and infraorbital electrodes. The impendence of all recording electrodes was kept below $3 \mathrm{k} \Omega$. The evoked potentials recording system was triggered by the onset of stimuli. The sampling rate was $200 \mathrm{kHz}$ and the sweep time was $1500 \mathrm{~ms}$. The evoked potentials were filtered with a band-pass at 0.1-30 Hz.

For controlling the effect of artifacts from the environment or the stimulator, we performed a control test, in which evoked potentials were recorded as previously described, except that the stimulator was applied above the stimulation site without skin contact. The formal test was performed only when there was no definite waveform in the control test. To prevent interference by the possible startle induced by the first heat stimulus, its evoked potential was not included in the recordings; formal recordings began from the next stimulus. The recordings with motion artifacts were discarded. The tracings with perception of stimuli but without obvious evoked responses were included. In total, 16 artifact-free tracings were included for analysis. To prevent interference from the total number of heat stimuli, recordings with more than 30 heat stimuli were not used in the analysis (the total number of stimuli was less than 25 in most subjects).

Preliminary Analysis of CHEPs. Figure 1A shows typical records of 16 superimposed tracings and their corresponding averaged tracing from a 35-year-old man with stimulation of the upper limb. The averaged tracing had a well-defined negative peak, designated $\mathrm{N} 1$, followed by a positive peak, designated P1. Thus CHEP parameters included N1 latency, N1 amplitude, P1 latency, P1 amplitude, and N1-P1 amplitude. Contact heat stimulation of the lower limb yielded similar tracings (Fig. 1B). We then performed preliminary experiments to determine: (1) reproducibility and (2) the peripheral conduction velocity of CHEP.

To determine reproducibility, the same procedures were repeated on 15 subjects at 1 month after the first examination. Similarly, CHEP waveforms

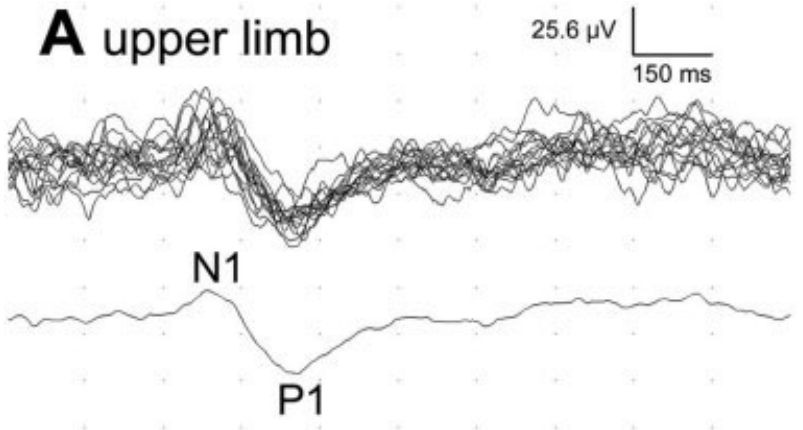

\section{B lower limb}

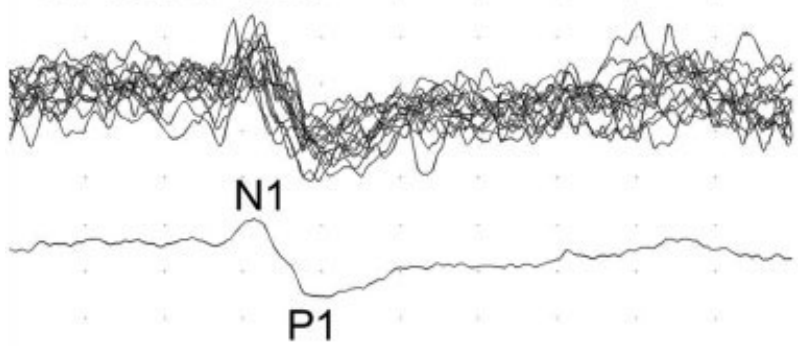

FIGURE 1. Tracings of contact heat-evoked potentials. The upper traces show the 16 overlapped tracings of CHEP on stimulation of the upper limb (A) and the lower limb (B). The lower trace shows the averaged tracing from the corresponding stimulation. For this subject, the $\mathrm{N} 1$ and $\mathrm{P} 1$ latencies are $387 \mathrm{~ms}$ and $555 \mathrm{~ms}$, respectively, in $\mathbf{A}$, and $\mathrm{N} 1$ and $\mathrm{P} 1$ amplitudes are $15 \mu \mathrm{V}$ and $30.3 \mu \mathrm{V}$. In B, the $\mathrm{N} 1$ and $\mathrm{P} 1$ latencies are $471 \mathrm{~ms}$ and 600 ms, respectively, with $\mathrm{N} 1$ and $\mathrm{P} 1$ amplitudes of $19.8 \mu \mathrm{V}$ and $22.3 \mu \mathrm{V}$.

were recorded in all these subjects during the second examination. The CHEP parameters from the first examination were highly correlated with those from the second examination $(r=0.95, P<0.0001$ for latency, and $r=0.84, P<0.0001$ for amplitude).

To understand the fiber type stimulated by the contact heat, we obtained CHEP data from an additional stimulation site near the $\mathrm{C} 7$ paraspinal process (proximal stimulation) in 13 subjects ( 8 men and 5 women) and calculated the peripheral conduction velocity in the upper limb. Proximal and distal stimulation yielded similar tracings (Fig. 2); the response latency on proximal stimulation was shorter than with distal stimulation. The average conduction velocity in the upper limb was $10.79 \pm 5.02 \mathrm{~m} / \mathrm{s}(4.28-$ $21.85 \mathrm{~m} / \mathrm{s}$ ) over the range of A $\delta$ fibers. ${ }^{16}$ Peripheral conduction velocity was similar for male and female subjects $(11.36 \pm 5.36 \mathrm{~m} / \mathrm{s}$ in males and $9.88 \pm 4.86$ $\mathrm{m} / \mathrm{s}$ in females, $P=0.94$ ).

Data Analysis. Analysis of the recorded evoked potentials was performed by the EP Vue system (Nicolet Biomedical, Madison, Wisconsin). For each sub- 


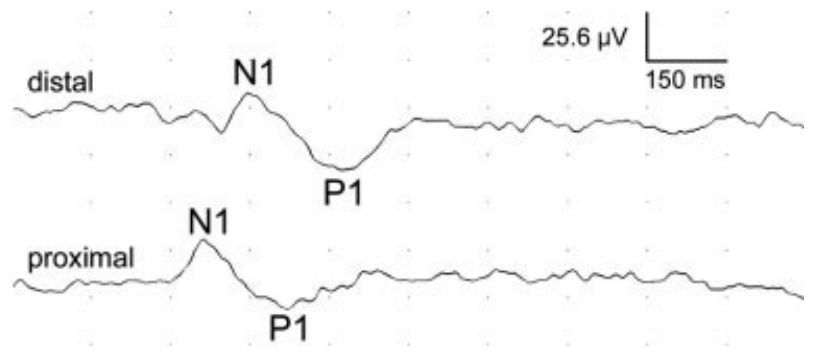

FIGURE 2. Contact heat-evoked potentials from proximal and distal stimulation sites of the upper limb. The tracings come from a male subject. Stimulation at the distal forearm produced an N1 latency of $447 \mathrm{~ms}$ (upper tracing), whereas more proximal stimulation in the C7 paraspinal area led to an N1 latency of $363 \mathrm{~ms}$ (lower tracing). The distance between the two stimulation site was $65 \mathrm{~cm}$, so that peripheral conduction velocity was calculated as $7.74 \mathrm{~m} / \mathrm{s}$.

ject, a total of 16 CHEP traces from the upper limb and lower limb, respectively, were averaged. Numerical variables are expressed as mean $\pm \mathrm{SD}$, and compared with $t$-tests. Graphic evaluation of the correlations between variables was analyzed with the slope of the regression line, its $\mathrm{SD}$, and $95 \%$ confidence interval. Slopes were analyzed using GraphPad Prism (GraphPad Software, San Diego, California). Both forward and backward stepwise linear regressions were performed using Stata statistical software (StataCorp, College Station, Texas) and SPSS (SPSS, Inc., Chicago, Illinois). Results from both versions were similar, and the presentation was based on the backward version. The correlation was explored further with multiple linear regression analysis. Analyses were performed based on the averaged tracing. For evaluating the influence of age, gender, height, or limb length on CHEP data, the latency or amplitude of the averaged CHEPs was set as the dependent variable, and age, gender, height, and length of limbs were independent variables. For exploring the association of pain perception with age or CHEP, the mean VRS was set as the dependent variable, and age, latency, or amplitude of the averaged CHEPs were set as independent variables. Results were considered significant at $P<0.05$.

\section{RESULTS}

Effects of Aging on CHEP. Heat stimulation evoked characteristic waveforms in all subjects. CHEP latencies for upper-limb stimulation were shorter than those for lower limbs (N1: $398.63 \pm 28.55 \mathrm{~ms}$ vs. $449.03 \pm 32.21 \mathrm{~ms}$, respectively, $P<0.0001$; P1: $541.63 \pm 37.92 \mathrm{~ms}$ vs. $595.41 \pm 39.24 \mathrm{~ms}, P<$
0.0001). The N1-P1 interpeak amplitudes were relatively higher for upper-limb than lower-limb responses $(42.30 \pm 12.57 \mu \mathrm{V}$ vs. $39.67 \pm 12.03 \mu \mathrm{V} ; P=$ $0.043)$. The $\mathrm{N} 1$ amplitudes and $\mathrm{P} 1$ amplitudes were similar in upper and lower limbs (N1: $18.97 \pm 9.19$ $\mu \mathrm{V}$ and $17.93 \pm 8.67 \mu \mathrm{V}$, respectively, $P=0.21$; $\mathrm{P} 1$ : $23.33 \pm 8.79 \mu \mathrm{V}$ and $21.79 \pm 6.82 \mu \mathrm{V}, P=0.10)$.

We analyzed the relationships of age and gender with CHEP parameters. N1 and P1 latencies were linearly correlated with age in both upper limb and lower limbs (Fig. 3A and B). Similarly, except for N1 amplitude of the lower limbs, the N1 amplitude of the upper limbs and the P1 and N1-P1 amplitudes of both upper and lower limbs were linearly correlated with age (Fig. 3C-E). Women had shorter N1 and P1 latencies than men (N1: $386.68 \pm 26.25$ ms vs. $412.03 \pm 25.13 \mathrm{~ms}$, respectively, and P1: $532.97 \pm 40.41 \mathrm{~ms}$ vs. $551.33 \pm$ $32.87 \mathrm{~ms}$ for the upper limb; N1: $433.11 \pm 24.16 \mathrm{~ms}$ vs. $466.88 \pm 30.97 \mathrm{~ms}$, and P1: $579.05 \pm 40.68 \mathrm{~ms}$ vs. $613.76 \pm 28.32 \mathrm{~ms}$ for the lower limb, respectively; Fig. $4 \mathrm{~A}$ and $\mathrm{B})$. The P1 and N1-P1 amplitudes for the lower limb were significantly higher in women than in men (Fig. 4C and D).

The heights of men were greater than those of women $(169.96 \pm 7.38 \mathrm{~cm}$ vs. $158.57 \pm 6.19 \mathrm{~cm}$, respectively; $P<0.001)$. The limb lengths of men were longer than those of women $[86.70 \pm 5.54 / 99.30 \pm$ $5.31 \mathrm{~cm}$ (upper/lower) in men and $79.66 \pm 4.25 /$ $92.84 \pm 4.06 \mathrm{~cm}$ (upper/lower) in women; both $P<$ $0.001]$. Because anthropometric variables such as height and the limb length may affect CHEP latencies, we analyzed the association of CHEP latencies with anthropometric factors. By simple linear regression, the N1 latency of the lower limb was positively correlated with body height (Fig. 3F) but not with length of the lower limb. The correlations in the upper limbs were not significant. We further analyzed these parameters modeled with multiple linear regression. In these models, each CHEP parameter was set as a dependent variable, and age, gender, body height, and length of the upper or lower limb were defined as independent variables (Table 1). The N1-P1 amplitudes of upper and lower limbs were negatively correlated with age. The N1 latencies of upper and lower limbs were correlated with gender: women had shorter latencies, independent of the effects of height and limb length. Thus, N1 latency and N1-P1 amplitude were used as measured CHEP parameters in the following analysis.

Effects of Aging on Pain Perception by Contact Heat Stimulation. We examined whether there were ageassociated changes in pain perception and whether pain perceptions had corresponding physiological responses based on CHEP findings. 

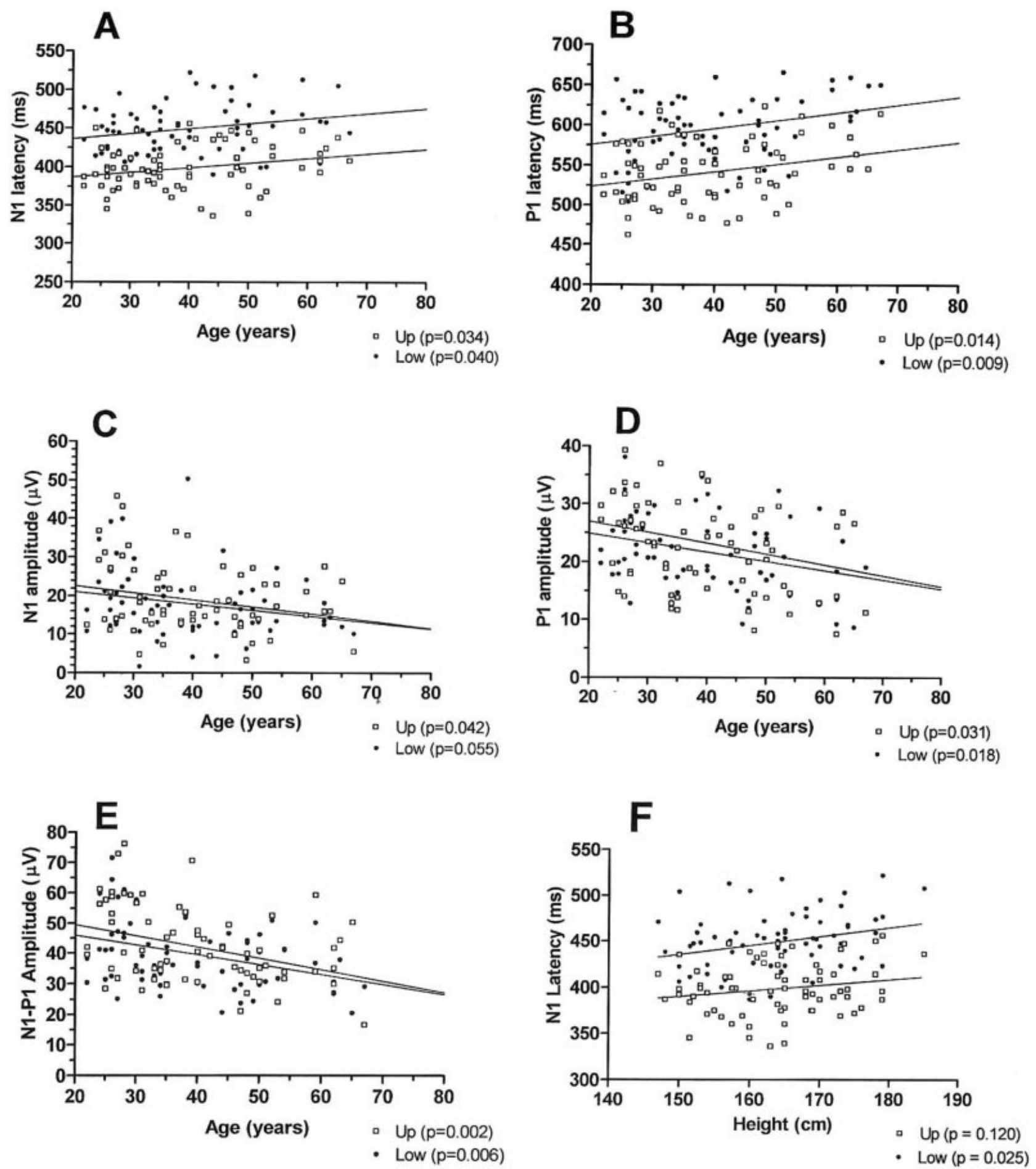

FIGURE 3. Age and parameters of contact heat-evoked potentials. CHEP parameters are analyzed by linear regression model with age: (A) for N1 latency; (B) for P1 latency; (C) for N1 amplitude; (D) for P1 amplitude; and (E) for N1-P1 amplitude. (F) Relationship to height. Latencies and amplitudes are linearly correlated with age with different level of statistical significance. Up: upper limb; Low: lower limb; p: $P$-value for slope. Solid line represents the linear regression line.

The mean VRS of the subjects was $5.72 \pm 0.96$ in the upper and $5.73 \pm 0.94$ in the lower limbs; both were in the range of mild to moderate pain. The mean VRS was negatively correlated with age (Fig. $5 \mathrm{~A})$. The mean VRS of women was higher than that of men ( $5.97 \pm 0.89$ vs. $5.43 \pm 0.97$, respectively, for 

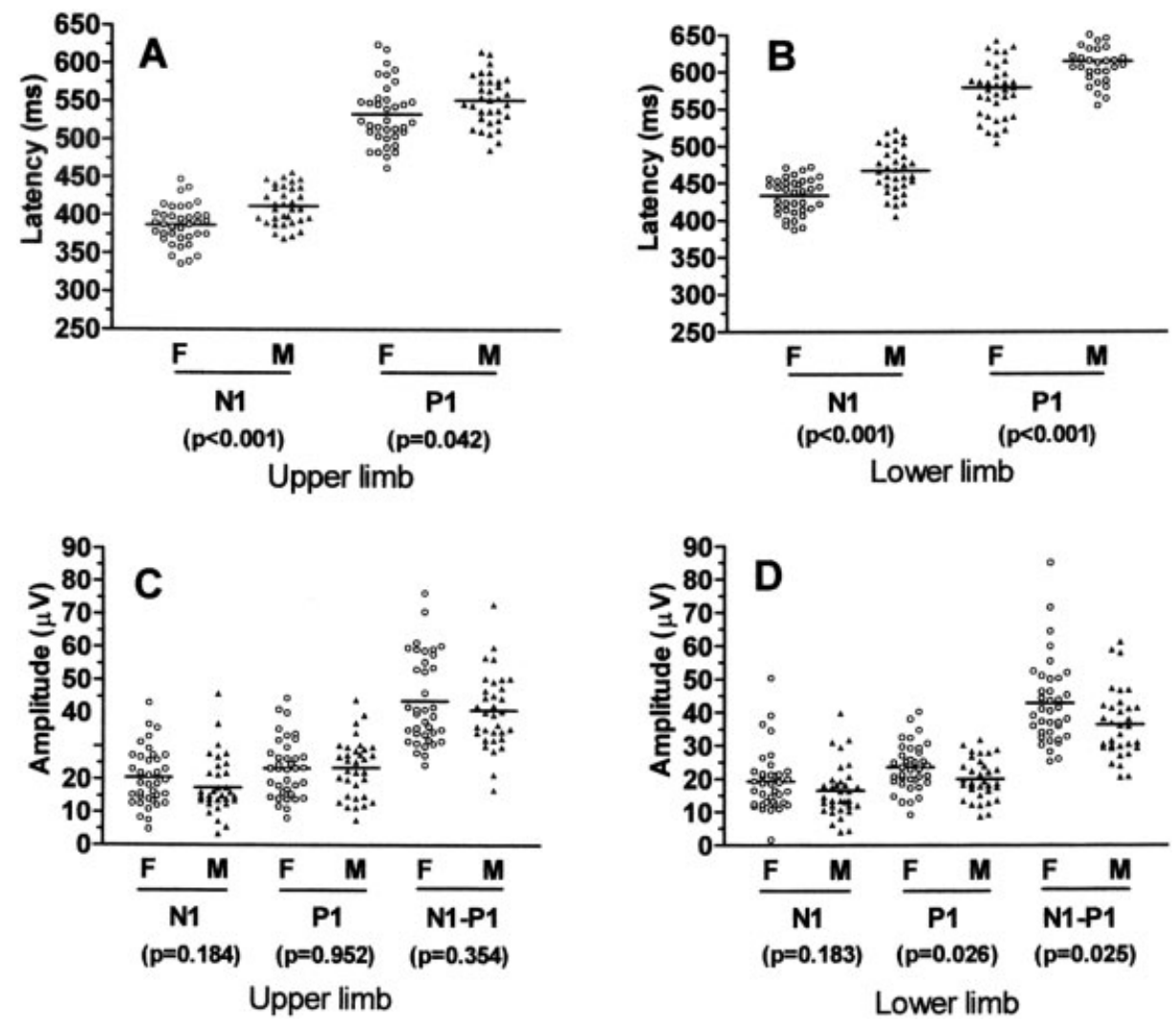

FIGURE 4. Effects of gender on parameters of contact heat-evoked potentials. CHEP parameters of female and male subjects are compared with $t$-tests. Comparison of N1 and P1 latencies of CHEPs in the upper (A) and lower limbs (B). Effects of gender on N1, P1, and N1-P1 amplitudes of CHEPs in the upper limbs (C) and lower limbs (D). F: female; M: male; $p$ : $P$-value for $t$-test.

the upper limb; $6.04 \pm 0.77$ vs. $5.38 \pm 1.00$ for the lower limb; Fig. 5B). The mean VRS was linearly correlated with N1 latencies (Fig. 5C) and N1-P1 amplitude (Fig. 5D). Because of the significant in- fluences of age on N1-P1 amplitudes and gender on N1 latencies, we further analyzed the effects of CHEP parameters on VRS with multiple linear regression models. The mean VRS was positively cor-

Table 1. Effect of age, gender, body height, and limb length on contact heat-evoked potential by multiple linear regression analysis.

\begin{tabular}{llllll}
\hline & & \multicolumn{4}{c}{$\beta, t, P$} \\
\cline { 3 - 6 } Model & \multicolumn{1}{c}{$R^{2}, P$} & \multicolumn{1}{c}{ Age } & \multicolumn{1}{c}{ Gender } & \multicolumn{1}{c}{ Body height } & \multicolumn{1}{c}{ Limb length } \\
\hline Upper limb & & & & & \\
N1 latency & $0.249,0.0008^{*}$ & $0.433,1.56,0.124$ & $27.499,3.21,0.002^{*}$ & $-0.828,-0.78,0.438$ & $0.875,0.61,0.547$ \\
N1 amplitude & $0.091,0.18$ & $0.205,2.08,0.041^{*}$ & $0.695,0.23,0.819$ & $0.315,0.84,0.406$ & $-0.268,-0.52,0.603$ \\
P1 latency & $0.167,0.0167^{*}$ & $0.756,1.95,0.056$ & $22.138,1.85,0.069$ & $-2.500,-1.68,0.097$ & $3.230,1.60,0.115$ \\
P1 amplitude & $0.072,0.2975$ & $-0.186,-1.96,0.054$ & $0.555,0.19,0.851$ & $-0.151,-0.42,0.678$ & $0.254,0.51,0.610$ \\
N1-P1 amplitude & $0.147,0.0334^{*}$ & $-0.391,-3.01,0.004^{*}$ & $-0.141,-0.04,0.972$ & $-0.466,-0.94,0.352$ & $0.522,0.77,0.444$ \\
Lower limb & & & & & \\
N1 latency & $0.330,<0.0001^{*}$ & $0.527,1.77,0.081$ & $31.954,3.46,0.001^{*}$ & $1.199,1.00,0.319$ & $-2.044,-1.23,0.225$ \\
N1 amplitude & $0.077,0.2618$ & $0.140,1.48,0.143$ & $3.077,1.05,0.296$ & $-0.219,-0.58,0.564$ & $0.283,0.54,0.594$ \\
P1 latency & $0.276,0.0003^{*}$ & $0.711,1.88,0.064$ & $39.889,3.41,0.001^{*}$ & $-1.198,-0.79,0.431$ & $1.021,0.48,0.631$ \\
P1 amplitude & $0.141,0.0396^{*}$ & $-0.125,-1.75,0.084$ & $-4.246,-1.92,0.060$ & $0.113,0.40,0.694$ & $-0.050,-0.12,0.901$ \\
N1-P1 amplitude & $0.167,0.0168^{*}$ & $-0.265,-2.14,0.036^{*}$ & $-7.324,-1.91,0.061$ & $0.332,0.67,0.507$ & $-0.332,-0.48,0.634$ \\
\hline
\end{tabular}

The analysis is based on multiple linear regression model: the latency or amplitude as the dependent variable, with age, gender, body height, and limb length as independent variables $\mathrm{R}^{2}$, coefficient of determination for each model; $\beta$, standardized coefficient; $t, t$-value for each independent variable; $p$, $P$-value for $\mathrm{R}^{2}$ or $\beta$. ${ }^{*} \mathrm{P}<0.05$ 
related with $\mathrm{N} 1-\mathrm{P} 1$ amplitude, independent of age $(P=0.029)$, and was negatively correlated with N1 latencies, independent of gender $(P=0.019)$, in the lower limb.

\section{DISCUSSION}

We found that: (1) CHEP amplitude was dependent on age; (2) VRS was age- and gender-dependent; and (3) pain perception measured by VRS was linearly correlated with CHEP latencies and amplitudes.

Two lines of data suggest that the CHEP is mediated by A $\delta$ fibers. First, the N1 latencies were similar to those of the late component of LEPs. ${ }^{3,38}$ The CHEP latencies in our series were relatively longer than those of LEPs, probably due to a longer time necessary to activate cutaneous receptors. Second, the peripheral conduction velocities of CHEPs were in the range of $A \delta$ fibers. ${ }^{16}$ The CHEP represents the cerebral responses to thermal stimuli with a larger stimulation area; this approach thus simulates the actual experience of thermal pain compared with other approaches. ${ }^{1,6}$

The present study indicates that aging has profound effects on the amplitude of CHEPs and on pain perception. Increased age is associated with reduced amplitude of CHEPs and a decreased painintensity rating. This observation provides physiological evidence for the fact that thermal pain thresholds are elevated ${ }^{11,21}$ and the subjective rating of noxious stimuli is decreased in the elderly. ${ }^{22}$ Aging influences the perception of thermal and noxious stimuli in different dimensions (e.g., pain in the cutaneous tissues, deep tissues, and viscera) and
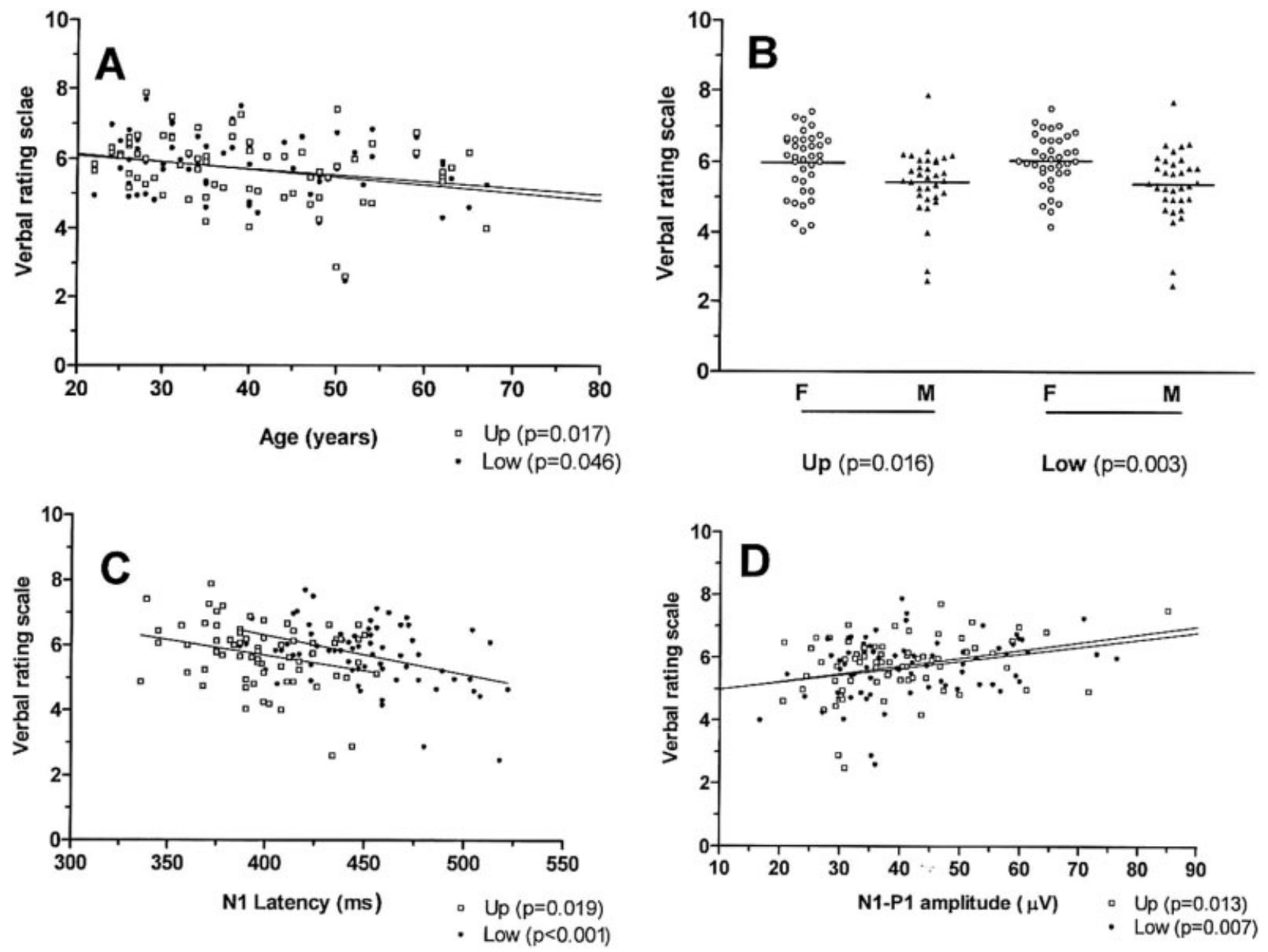

FIGURE 5. The influence of age, gender, and parameters of contact heat-evoked potentials on the verbal rating scale (VRS) of pain perception. (A) Influence of age on VRS, analyzed by linear regression. (B) Influence of gender on VRS, analyzed by $t$-test. (C) Scatterplot shows the linear correlation between N1 latency of CHEPs and VRS. (D) VRS is linearly correlated with N1-P1 amplitude of CHEPs. Up: upper limb; Low: lower limb; p: $P$-value for slope (age, latency, and amplitude) and for $t$-test (gender). The solid line is the linear regression line. 
various mechanisms may underlie these differences.9,27,36 CHEPs are integrated responses to contact heat stimulation at the skin; hence, differences in the pattern of skin innervation may underlie the effect of age. The abundance of skin innervation, particularly of free nerve endings in the epidermis, can be demonstrated with neural markers, 20,24 including protein gene product 9.5, calcitonin generelated peptide, and substance P. ${ }^{13}$ Our group and others have previously shown that skin innervation is reduced with age in both upper and lower limbs, and there is a linear decline in epidermal innervation with age. ${ }^{2,5}$ In addition, the density of both myelinated and unmyelinated nerve fibers in peripheral nerves decreases with age. ${ }^{15}$ The reduction in skin innervation and fiber densities of peripheral nerves could decrease the peripheral input of heat impulses and result in the reduction of N1-P1 amplitude and of pain intensity. Further, the possibility of transmission decay in the elderly at different levels of the neural axis cannot be excluded. For example, agerelated differences occur in the synthesis, transport, and action of many neurotransmitters in the spinal cord and brain. ${ }^{18,29}$ These age-related changes may be associated with alterations in pain sensitivity.

An intriguing observation from this study is the strong effect of gender on the latencies of CHEPs, independent of age. Several observations may explain why thermal stimuli, such as in our setting, might induce a faster activation of nociception in women. First, skin innervation is more abundant in women than in men, regardless of age. ${ }^{5}$ Second, thermal thresholds as measured by quantitative sensory testing are lower in women than in men, ${ }^{23}$ and in general women have a lower threshold to a wide range of noxious stimuli. ${ }^{33}$ Third, skin thickness is less in women, which might lead to more rapid activation of nociceptors. ${ }^{30}$ Fourth, gender is indeed an independent parameter of pain perception ${ }^{17,42}$ and women seem to perceive more unpleasantness than men through central mechanisms, such as differing brain activation or temporal summation. ${ }^{28,31}$ Based on our analysis of peripheral conduction velocities, the gender effects on CHEP latencies could not be explained fully by the difference in peripheral conduction velocities between men and women. Taken together, these findings suggest that gender modulates the time for activation of peripheral receptors or central processing from the spinal cord to the cerebral cortex.

This work was supported by a grant from National Health Research Institute, Taiwan, to S. T. Hsieh (NHRI-EX94-9323NI), and a grant from National Taiwan University Hospital, Taiwan, to C. C. Chao (95N09).

\section{REFERENCES}

1. Arendt-Nielsen L, Chen AC. Lasers and other thermal stimulators for activation of skin nociceptors in humans. Neurophysiol Clin 2003;33:259-268.

2. Besne I, Descombes C, Breton L. Effect of age and anatomical site on density of sensory innervation in human epidermis. Arch Dermatol 2002;138:1445-1450.

3. Bromm B, Treede RD. Human cerebral potentials evoked by $\mathrm{CO}_{2}$ laser stimuli causing pain. Exp Brain Res 1987;67:153162.

4. Chakour MC, Gibson SJ, Bradbeer M, Helme RD. The effect of age on A delta- and C-fibre thermal pain perception. Pain 1996;64:143-152.

5. Chang YC, Lin WM, Hsieh ST. Effects of aging on human skin innervation. Neuroreport 2004;15:149-153.

6. Chen AC, Niddam DM, Arendt-Nielsen L. Contact heat evoked potentials as a valid means to study nociceptive pathways in human subjects. Neurosci Lett 2001;316:79-82.

7. Cruccu G, Anand P, Attal N, Garcia-Larrea L, Haanpaa M, Jorum E, et al. EFNS guidelines on neuropathic pain assessment. Eur J Neurol 2004;11:153-162.

8. Davis KD. Neurophysiological and anatomical considerations in functional imaging of pain. Pain 2003;105:1-3.

9. Gibson SJ, Farrell M. A review of age differences in the neurophysiology of nociception and the perceptual experience of pain. Clin J Pain 2004;20:227-239.

10. Granovsky Y, Matre D, Sokolik A, Lorenz J, Casey KL. Thermoreceptive innervation of human glabrous and hairy skin: a contact heat evoked potential analysis. Pain 2005;115:238-247.

11. Harkins SW, Price DD, Martelli M. Effects of age on pain perception: thermonociception. J Gerontol 1986;41:58-63.

12. Heft MW, Cooper BY, O'Brien KK, Hemp E, O'Brien R. Aging effects on the perception of noxious and non-noxious thermal stimuli applied to the face. Aging 1996;8:35-41.

13. Hilliges M, Wang L, Johansson O. Ultrastructural evidence for nerve fibers within all vital layers of the human epidermis. J Invest Dermatol 1995;104:134-137.

14. Inui K, Tran TD, Hoshiyama M, Kakigi R. Preferential stimulation of Adelta fibers by intra-epidermal needle electrode in humans. Pain 2002;96:247-252.

15. Jacobs JM, Love S. Qualitative and quantitative morphology of human sural nerve at different ages. Brain 1985;108:897-924.

16. Kakigi R, Endo C, Neshige R, Kuroda Y, Shibasaki H. Estimation of conduction velocity of A delta fibers in humans. Muscle Nerve 1991;14:1193-1196.

17. Keogh E, Herdenfeldt M. Gender, coping and the perception of pain. Pain 2002;97:195-201.

18. Ko ML, King MA, Gordon TL, Crisp T. The effects of aging on spinal neurochemistry in the rat. Brain Res Bull 1997;42:9598.

19. Larrea-Garcia L, Frot M, Magnin M, Maugiere F. Intracortical recordings of pain related laser evoked potentials in the human cingulate cortex. Clin Neurophysiol 2006;117(suppl): S71-S72.

20. Lauria G, Cornblath DR, Johansson O, McArthur JC, Mellgren SI, Nolano M, et al. EFNS guidelines on the use of skin biopsy in the diagnosis of peripheral neuropathy. Eur J Neurol 2005; 12:747-758.

21. Lautenbacher S, Strian F. Similarities in age differences in heat pain perception and thermal sensitivity. Funct Neurol 1991;6:129-135.

22. Li SF, Greenwald PW, Gennis P, Bijur PE, Gallagher EJ. Effect of age on acute pain perception of a standardized stimulus in the emergency department. Ann Emerg Med 2001;38:644647.

23. Lin YH, Hsieh SC, Chao CC, Chang YC, Hsieh ST. Influence of aging on thermal and vibratory thresholds of quantitative sensory testing. J Peripher Nerv Syst 2005;10:269-281. 
24. Lin YW, Tseng TJ, Lin WM, Hsieh ST. Cutaneous nerve terminal degeneration in painful mononeuropathy. Exp Neurol 2001;170:290-296.

25. Magerl W, Ali Z, Ellrich J, Meyer RA, Treede RD. C- and A delta-fiber components of heat-evoked cerebral potentials in healthy human subjects. Pain 1999;82:127-137.

26. Millan MJ. The induction of pain: an integrative review. Progr Neurobiol 1999;57:1-164.

27. Moore AR, Clinch D. Underlying mechanisms of impaired visceral pain perception in older people. J Am Geriatr Soc 2004;52:132-136.

28. Paulson PE, Minoshima S, Morrow TJ, Casey KL. Gender differences in pain perception and patterns of cerebral activation during noxious heat stimulation in humans. Pain 1998; 76:223-229.

29. Racagni G, Rovescalli AC, Galimberti R, Brunello N. Neurotransmitter systems and receptor plasticity in brain aging. Mod Probl Pharmacopsychiatry 1989;23:21-27.

30. Sandby-Moller J, Poulsen T, Wulf HC. Epidermal thickness at different body sites: relationship to age, gender, pigmentation, blood content, skin type and smoking habits. Acta Derm Venereol 2003;83:410-413.

31. Sarlani E, Grace EG, Reynolds MA, Greenspan JD. Sex differences in temporal summation of pain and aftersensations following repetitive noxious mechanical stimulation. Pain 2004;109:115-123.

32. Shy ME, Frohman EM, So YT, Arezzo JC, Cornblath DR Giuliani MJ, et al. Quantitative sensory testing: report of the Therapeutics and Technology Assessment Subcommittee of the American Academy of Neurology. Neurology 2003;60: 898-904.
33. Soetanto AL, Chung JW, Wong TK. Are there gender differences in pain perception? J Neurosci Nurs 2006;38:172-176.

34. Sullivan EV, Rosenbloom M, Serventi KL, Pfefferbaum A Effects of age and sex on volumes of the thalamus, pons, and cortex. Neurobiol Aging 2004;25:185-192.

35. Tarkka IM, Treede RD. Equivalent electrical source analysis of pain-related somatosensory evoked potentials elicited by a $\mathrm{CO}_{2}$ laser. J Clin Neurophysiol 1993;10:513-519.

36. Thomas T, Robinson C, Champion D, McKell M, Pell M. Prediction and assessment of the severity of post-operative pain and of satisfaction with management. Pain 1998;75:177185.

37. Tong HC, Werner RA, Franzblau A. Effect of aging on sensory nerve conduction study parameters. Muscle Nerve 2004;29: 716-720.

38. Towell AD, Purves AM, Boyd SG. $\mathrm{CO}_{2}$ laser activation of nociceptive and non-nociceptive thermal afferents from hairy and glabrous skin. Pain 1996;66:79-86.

39. Truini A, Galeotti F, Romaniello A, Virtuoso M, Iannetti GD, Cruccu G. Laser-evoked potentials: normative values. Clin Neurophysiol 2005;116:821-826.

40. Valeriani M, Le Pera D, Niddam D, Chen AC, Arendt-Nielsen L. Dipolar modelling of the scalp evoked potentials to painful contact heat stimulation of the human skin. Neurosci Lett 2002;318:44-48.

41. Willis WD, Westlund KN. Neuroanatomy of the pain system and of the pathways that modulate pain. J Clin Neurophysiol 1997;14:2-31.

42. Wise EA, Price DD, Myers CD, Heft MW, Robinson ME. Gender role expectations of pain: relationship to experimental pain perception. Pain 2002;96:335-342. 